\title{
Effectiveness of Five-Level Emergency Severity Index Triage System Compared With Three-Level Spot Check: An Iranian Experience
}

\author{
Mohammadreza Maleki, ${ }^{1}$ Razieh Fallah, ${ }^{2,}$ Leila Riahi, ${ }^{3}$ Sajad Delavari, ${ }^{4}$ and Satar Rezaei ${ }^{5}$ \\ ${ }_{1}^{1}$ Department of Health Services Management, School of Health Management and Information Sciences, Iran University of Medical Sciences, Tehran, IR Iran \\ ${ }^{2}$ Amol Imam Reza Hospital, Mazandaran University of Medical Sciences, Sari, IR Iran \\ 3 Department of Health Services Management, Faculty of Management and Economics, Science and Research Branch, Islamic Azad University, Tehran, IR Iran \\ ${ }^{4}$ Health Human Resources Research Center, School of Management and Information Sciences, Shiraz University of Medical Sciences, Shiraz, IR Iran \\ ${ }_{5}^{5}$ Research Center for Environmental Determinants of Health, Kermanshah University of Medical Sciences, Kermanshah, IR Iran \\ ${ }^{*}$ Corresponding author: Razieh Fallah, Amol Imam Reza Hospital, Mazandaran University of Medical Sciences, P. O. Box: 4614937597, Sari, IR Iran. Tel: +98-1143272016, Fax: +98-1143272011, \\ E-mail: fallahrazieh@gmail.com
}

Received 2015 April 15; Revised 2015 June 14; Accepted 2015 July 16.

\begin{abstract}
Background: Triage for patients' prioritization in the emergency department is a suitable solution to decrease overcrowding. Different methods are used for prioritization that needs effectiveness evaluation.

Objectives: The aim of this study was to assess the effectiveness of the emergency severity index(ESI)5-level triage system in contrast with spot check triage.

Patients and Methods: Data for this quasi-experimental study were extracted using a form to review 770 records of patients referred to emergency department of Imam Khomeini hospital (in Sari, north of Iran) during two separated periods each for four months; the first from 20th March to 19th July 2010 and the other from 21 March to 20 July 2011. The method used in the first time was spot check triage and the second one ESI triage. Data were processed with descriptive statistics and analyzed using independent samples t-test $(\mathrm{CI}=95 \%)$.

Results: Increase from 6.46 to 8.92 minutes in the average time from patient arrival to being visited by a physician $(\mathrm{P}<0.001)$ and increase in average time from physician visit to receive the first nursing care from 7.68 to 15.89 minutes were significant $(\mathrm{P}<0.001)$. The average waiting time for laboratory services was significantly decreased from 112.3 to $84.1(\mathrm{P}=0.033)$. Increase in the average waiting time for radiology, decrease in average waiting time for sonography, average length of stay in the emergency department, and number of patients per emergency bed were not significant.

Conclusions: Between the two systems of triage, ESI was more effective than the spot check and in the spatial and temporal domain of research, was a successful method in improving some indicators of emergency and improving the performance indices. Hospitalmanagers by implementation of ESI system can take a step toward new health policies and improve the processes as key tools of continuous quality improvement system.
\end{abstract}

Keywords: Emergency Service, Triage, Comparative Effectiveness Research

\section{Background}

Nowadays, hospitals emergency departments are one of the most important departments in all health care system (1). Overcrowding in emergency departments is a problem that threatens patients' health (2); therefore, hospital triage is performed as an effective solution for solving this problem. Triage is defined as patients' prioritization regarding existent resources (3).

Increase in patients' workflow time in emergency department leads to more problems in other hospital wards and inter-department different processes (4), which can limit patients' access to cares (5). Kyriacou et al. (6) state that time studies are effective methods to identify delays in patient care and interventions should be aimed to reduce the length of stay in emergency. Many researchers seek to identify different ways for reducing waiting time in emergency department. For example, $\mathrm{Ng}$ et al. (7) stat- ed that lean principles can facilitate patient flow in emergency departments and accordingly, patient satisfaction would be increased by reduction in service time. In another research, Spaite et al. (8) redesigned a rapid process for emergency department and resulted in decrease in waiting times and improvement in patients' satisfaction. Moreover, McGillicuddy et al. (9) tried to decrease the average time to be visited by a physician, the same as Paulson (10), which indicated a correlation between number of nurses and less waiting time.

On the other hand, triage system is used for communication between hospital personnel in emergency department and patients should be visited by a physician immediately (11). Thus, different methods for patient prioritization are used in emergency departments that vary in effectiveness. The emergency severity index (ESI) is a

Copyright (C) 2015, Kashan University of Medical Sciences. This is an open-access article distributed under the terms of the Creative Commons Attribution-NonCommercial 4.0 International License (http://creativecommons.org/licenses/by-nc/4.0/) which permits copy and redistribute the material just in noncommercial usages, provided the original work is properly cited. 
five-level triage scale for prioritization ( 1 indicates most acute and 5 indicates least acute). The principle role of ESI is to facilitate prioritization of patients based on their urgency $(12,13)$.

ESI is recognized as a valid and accurate system, which prioritizes patients, as well as following their treatment process for better access to medical care and services (14). McHugh et al.(15) stated that ESI was the most commonly used triage system. ESI could be used in all emergency departments, including urban and rural settings and academic and community hospitals. Accordingly, Singer (16) reported high satisfaction rate among most emergency department professionals who used ESI.

Furthermore, Christ et al. (17) reported that triage instruments that sort patients in five levels were better than those in three levels regarding validity and reliability. Moreover, Durani et al. (18) reported ESI version 4 as a reliable tool for triage assessments in pediatric patients, which was highly accepted by physicians and nurses.

Thus, improvement in triage is the aim of hospitals to improve clinical outcomes, especially in resource-limited settings (19). Most of previous studies proved ESI as one of the best methods in patients' prioritization in many countries. In Iran, emergency departments provide services to about 30 million patients and improvement in its structure is one of the priorities in Iran ministry of health and medical education. In this way, using ESI triage in Iran hospitals is new and had not proved its effectiveness.

\section{Objectives}

Previous studies performed in other countries used time study, comparing different triage instruments, effects of triage system on communication between health personnel in emergency department to evaluate the triage methods. As well, ESI triage system is fairly new in Iran and administrative policy of the ministry of health and medical education of Iran is to remove spot check triage systems and replace ESI triage system in Iran. Since, the ESI effect on performance indicators has not been studied in Iran, a quasi-experimental study was performed to evaluate the effectiveness of ESI, version 4 triage method compared with spot check. The research aimed to identify strengths and weaknesses of ESI to help emergency department directors and staff to amend and improve internal processes in emergency departments.

\section{Patients and Methods}

This quasi-experimental study was performed to survey the effectiveness of ESI five-level triage system, version 4 compared with spot check in Imam Khomeini Hospital, Sari, north of Iran. The hospital is a governmental, educational and general center, which has 328 approved beds with 18 wards and serves as a referral hospital in Mazandaran Province.
Effectiveness analysis mainly focused on emergency departments' time indicators. Data about emergency department admission retrieved for two periods of time each for four months. The first period was from 20th March to 19th July 2010 and the second one from 21th March to 20th July 2011. In these two periods, two different triage systems were used in the emergency department. Three-level triage system was used in the first period named spot check with three levels including emergent, urgent, and not urgent. In the second period, comprehensive five-level triage system named ESI, version 4, was used with five levels.

Additionally, it would be important to account for potential differences in the patient population. We assessed patients' age and the average number of patients per emergency department bed to assure the similarity of two time periods. As well, we considered potential staff differences. This information for the two periods is presented in Tables 1 and 2.

Accordingly, the ESI and spot check were compared based on different time indicators including the average time to be visited by a physician, average time of delivering first nursing care, average time taken to receive the results of laboratory tests, average time taken to receive the report of radiology services, and average time taken to receive the report of sonography as dependent variables.

The study population included all patients triaged in emergency department of the hospital, which were about 6200 patients monthly. Krejcie and Morgan table was used to calculate sample size. Accordingly, a sample of 379 patients (20) was selected randomly for each period independently. To prevent loss of validity due to loss of sample, the sample size was multiplied by 1.02 and data were collected for 387 patients. For sampling, systematic random sampling was used to select the samples with sample interval of 16 . However, 272 patients in the first period and 274 patients in the second period did not have medical record; because they were discharged after triage and there was no need to set up a medical record. Thus, the only record for them was triage form.

Data were extracted using data collection forms and filled based on patients' medical records. For reliability, data collection forms were prepared in the format of chronometry of emergency department services' workflow and instruction of indicators for hospital emergency department (1) without technical changes in the content and structure of the forms. Validity of checklist was approved using experts' opinion such as emergency medicine specialists and officials of emergency department of Imam Khomeini Hospital. Three emergency medicine specialists and one PhD educated in nursing participated in validating checklist. According to their comments, some fields were reformed and the final approved checklist was prepared. The checklist had two main parts of demographic characteristics of patients and service delivery in emergency department. 
Extracted data were analyzed using SPSS software (11.5 by SPSS Inc.). Descriptive statistics such as frequency, mean, standard deviation and independent samples t-test were used for data analysis and the research confidence coefficient was determined at 95\% level.

The study protocol complied with the ethical guidelines of the 1975 Declaration of Helsinki.

\section{Results}

From all 387 patients triaged with spot check (the first period), 63\% were males and 37\% females and from 383 patients of ESI (second period), $48 \%$ were males and 52\% females. In addition, regarding patients' age in the two periods, triage services were delivered to similar patients (see Table 1 for comparing patients' age). As indicated in Table 1, mean of patients age in the first and second periods were around 35.7 and no significant difference was found $(\mathrm{P}=0.998)$.

Similarly, we considered the average number of patients per emergency department bed and total number of triage nurses in the two periods. Table 2 shows no considerable differences in these two periods. According to observations, in the both periods, triage nurses were al- most the same and no significant changes were made in manpower.

We also compared the number of patients categorized in different levels of triage. Since levels of two triage systems are not combinable, descriptive data are provided in Table 3.

Findings for time indicators are shown in Table 4. The average time of being visited by a physician was increased by 2.46 minutes, from 6.46 minutes in Spot check to 8.92 minutes in ESI $(\mathrm{P}<0.001)$. The average time of delivering first nursing care reached from 7.68 minutes in spot check to 15.89 minutes in ESI, which increased by 8.21 minutes $(\mathrm{P}<0.001)$. By reduction in the number of laboratory services in ESI compared to spot check, the mean time taken to receive the results of laboratory tests was decreased by 28.2 minutes, from 112.3 minutes in spot check to 84.1 minutes in ESI $(\mathrm{P}=0.033)$. In addition to reduction in the number of radiological services in ESI compared to spot check, the mean time taken to receive the report of radiology services reached from $40.4 \mathrm{~min}$ utes to 44.9 minutes $(\mathrm{P}=0.644)$. The mean time taken to receive the report of sonography decreased from 102.1 minutes in spot check to 63.4 minutes in ESI by 38.7 minutes reduction $(\mathrm{P}=0.171)$.

Table 1. Comparison of Patients' Age in Three-Level Spot Check and Five-Level Emergency Severity Index Systems ${ }^{\mathrm{a}}$

\begin{tabular}{|c|c|c|c|c|c|}
\hline \multirow{2}{*}{ Variable } & \multicolumn{2}{|c|}{ Triage Systems } & \multicolumn{3}{|c|}{ Test } \\
\hline & $\begin{array}{c}\text { Three-Level Triage } \\
\text { Spot Check }\end{array}$ & $\begin{array}{l}\text { Five-Level Triage } \\
\text { ESI System }\end{array}$ & $\mathbf{T}$ & df & $\mathbf{P}$ \\
\hline Age $^{b}$ & $35.70 \pm 20.668$ & $35.74 \pm 19.580$ & 0.015 & 220 & 0.988 \\
\hline
\end{tabular}

a Abbreviations: df, degree of freedom; ESI, emergency severity index.

${ }^{\mathrm{b}}$ Data are presented as mean \pm SD.

Table 2. Comparison of Triage Man Power and Bed Indices in Three-Level Spot Check and Five-Level Emergency Severity Index Systems

\begin{tabular}{lcc}
\hline Triage Systems & $\begin{array}{c}\text { The Average Number of Patients per } \\
\text { Emergency Department Bed }\end{array}$ & Number of Triage Nurse \\
\hline Three-level triage spot check & 0.42 & 7 \\
Five-level Triage ESI system & 0.38 & 7 \\
\hline
\end{tabular}

Table 3. Categorization of Patients in Three-Level and Five- Level Systems ${ }^{\mathrm{a}}$

\begin{tabular}{lccccccccc}
\hline \multirow{2}{*}{ Levels } & \multicolumn{3}{c}{ Spot Check Triage System } & \multicolumn{3}{c}{ ESI Triage System } \\
\cline { 2 - 9 } & Emergent & Urgent & $\begin{array}{c}\text { Not ur- } \\
\text { gent }\end{array}$ & One & Two & Three & Four & Five \\
\hline Number of patients & 0 & 115 & 272 & 1 & 9 & 96 & 145 & 129 \\
\hline
\end{tabular}

\footnotetext{
a Abbreviation: ESI, emergency severity index.
} 
Maleki M et al.

\begin{tabular}{|c|c|c|c|c|c|}
\hline \multirow{2}{*}{ Index } & \multicolumn{2}{|c|}{ Three-Level Triage System Spot Check } & \multicolumn{2}{|c|}{ Five-Level Triage ESI System } & \multirow{2}{*}{ Test } \\
\hline & Frequency & Time, min $^{a}$ & Frequency & Time, $\min ^{\mathrm{a}}$ & \\
\hline $\begin{array}{l}\text { The average time from patient } \\
\text { arrival to being visited by a } \\
\text { physician }\end{array}$ & 387 & $6.46 \pm 9.96$ & 383 & $8.92 \pm 9.66$ & $\begin{array}{c}\mathrm{T}=-3.474, \mathrm{df}=768 \\
\mathrm{P}<0.001\end{array}$ \\
\hline $\begin{array}{l}\text { Time of delivering first nursing } \\
\text { care }\end{array}$ & 384 & $7.68 \pm 9.357$ & 114 & $15.89 \pm 13.473$ & $\begin{array}{c}\mathrm{T}=-6.085, \mathrm{df}= \\
146.792, \mathrm{P}<0.001\end{array}$ \\
\hline $\begin{array}{l}\text { Time taken to receive the result } \\
\text { of laboratory test }\end{array}$ & 77 & $112.3 \pm 82.7$ & 54 & $84.1 \pm 66.3$ & $\begin{array}{c}\mathrm{T}=2.162, \mathrm{df}= \\
126.618, \mathrm{P}=0.033\end{array}$ \\
\hline $\begin{array}{l}\text { Time taken to receive the report } \\
\text { of radiology services }\end{array}$ & 43 & $40.4 \pm 35.9$ & 41 & $44.9 \pm 51.7$ & $\begin{array}{c}\mathrm{T}=-0.463, \mathrm{df}=82, \mathrm{P} \\
=0.644\end{array}$ \\
\hline $\begin{array}{l}\text { Time taken to receive the report } \\
\text { of sonography as dependent } \\
\text { variables }\end{array}$ & 17 & $102.1 \pm 71$ & 17 & $63.4 \pm 88.9$ & $\begin{array}{c}\mathrm{T}=1.4, \mathrm{df}=32, \mathrm{P}= \\
0.171\end{array}$ \\
\hline
\end{tabular}

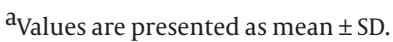

\section{Discussion}

Two periods were relatively similar regarding admitted patients and service delivery. Therefore, we could conclude that change in triage system was one of the main factors affecting time indicators.

Based on findings about the average time to be visited by a physician, independent samples t-test showed a significant difference in the average time in the first and second periods; ESI Triage had a significant impact on time to be visited by a physician and had led to increase this index in the hospital. Other studies such as McGillicuddy et al. (9) and $\mathrm{Ng}$ et al. (7) investigations reported decrease in this index and our findings do not match with others. Maybe, start of new project and slow pace of learning ESI triage by nurses in hospital can be considered as influencing factors on this increase.

Similarly, average time of delivering first nursing care was increased significantly in ESI compared with spot check. This is also inconsistent with the results of other researches such as Azizi-Naghdlou (21) and Paulson (10). This may be because of misunderstanding about nursing care in spot check in the first period. Indeed, in spot check system in the first period, due to misperception among triage nurses and failure to identify the triage process, screening by nurses in the first place was considered as a kind of nursing care inconsistent with the standard definition of nursing care. While, changes in the triage system resulted in right registration time of nursing care requested by physician. In fact, reorganization of new processes and improving methods led to increasing this index and its actual occurrence.

Regarding the time of laboratory services, two independent samples t-test showed a significant difference in the average time before and after intervention $(\mathrm{P}=0.033)$. Accordingly, ESI triage system led to reduction in this index in hospital. This is in contrast with the result of Hosseini et al. (22), Eghdam et al. (23), and Storrow et al.(24). ESI triage system classifies patients with focus on their scale of severity, which facilitates patients flow in different levels and predicts the right required resources. On the other hand, ESI triage nurses act better in screening patients and lead them into the treatment process. As a result, about a half of patients in this emergency department with trauma who needed radiology and sonography procedures were led to these units and determining the real needs of patients for laboratory services, caused laboratory workload adjustment, and thus shorter waiting time and queue.

Average waiting time for radiology services was reduced in ESI, but independent samples t-test did not show any significant difference in the average time before and after intervention $(P=0.644)$. ESI Triage system was not effective on average time for radiology services. This finding is inconsistent with the results of Hosseini et al.(22) and Azizi-Naghdlou (21).

Another reduction was observed in the average time taken to receive the report of sonography. Nonetheless, independent samples t-test did not show any significant difference in the average time before and after intervention $(\mathrm{P}=0.171)$. Therefore, ESI triage system was not effective on sonography services time. This is inconsistent with the results of Azizi-Naghdlou (21) and it seems that using a five-level triage system ESI represents a significant difference rate of index at two systems. Further inquiries revealed that number of sonography services for patients was equal in two periods. Minor and insignificant reduction in the index, perhaps is due to an increase in radiology specialist presence in radiology department, increase in the speed of service delivery or delivering emergency 
sonography by emergency medicine specialists to improve treatment process.

Five-level triage system has been reported effective on emergency action consistent with Eghdam et al. (23) and Singer et al. (16) who reported that most experts in the emergency department believed that ESI led to more satisfaction and users found that ESI is more accurate than the other models and improve teamwork in triage. Besides, McHugh et al. (15) in a study on samples of more than 3000 hospital stated that ESI was the most commonly used triage system in hospitals.

Christ et al. (17) expressed that triage instruments with five levels have priority on three-level instruments regarding validity and reliability and only the ESI has been validated in German-speaking countries. Furthermore, Durani et al. (18) expressed that ESI version 4 is a triage system with high agreement between physicians and nurses and a reliable tool for triage assessments in pediatric patients, which is consistent with Paulson's (10) results as well.

In this paper we compared ESI triage system with spot check in an emergency department for the first time in Iran. Since ESI was new compared with spot check, maybe nurses, physicians and other staff were not enough familiar with ESI and it might overshadow the findings of the present research. Therefore, more researches in other times and other context are needed to generalize the results. Moreover, we compared these two systems regarding emergency department time indicators. We recommend more studies be performed about other aspects of emergency department process. Similarly, patients and staff satisfaction are factors that should be addressed comparing the two triage systems in future studies.

Between the two triage systems, ESI played a significant role to facilitate prioritization of patients according to their urgency situation and patient streaming; getting the right patient to the right resources at the right place and at the right time and acted more effective than three-level triage system spot check. Also, in the time and place domain of research has been a successful model on the effect of time indicators of emergency and promotion of some indices.

According to our findings, ESI triage system is more suitable for Iran than the three-level system. Emergency severity index could help hospital managers, since they are faced with limited resources and they should make the best use of these limited resources to make the best possible outputs. Emergency severity index triage system could decrease the average time of emergency department process and result in patient health and satisfaction. Hospitals and other medical centers are suggested to use ESI to help them take a step toward processes improvement as a key tool for continuous quality improvement.

\section{Acknowledgments}

Authors would like to thank Mr. Seyed Mohammad Hoseininezhad, associate professor, department of emer- gency medicine, school of medicine, Mazandaran university of medical sciences, Sari, Iran and Amir Hosein Mirhaghi, Ph.D, school of nursing, Mashhad university of medical sciences, Mashhad, Iran, for their specialized advices on a domain of research and their kind cooperation.

\section{Footnotes}

Authors' Contribution:Study concept and design, data gathering, analysis, and interpretation: Razieh Fallah; critical revision of the manuscript for important intellectual content: Mohammadreza Maleki; administrative and technical support: Leila Riahi; drafting of the manuscript: Sajad Delavari; revising the manuscript: Satar Rezaei.

Funding/Support:Authors provided the financial resources needed to perform this research project without any financial assistance.

\section{References}

1. American-Hospital-Association. Trendwatch. Emergency departments: an essential access point to care. 2001.

2. Gordon JA, Billings J, Asplin BR, Rhodes KV. Safety net research in emergency medicine proceedings of the Academic Emergency Medicine Consensus Conference on "The Unraveling Safety Net. Acad Emerg Med. 2001;8(11):1024-9. [PubMed:11691663]

3. McNally S. Let's have standards for triage education and practice. AustEmerg Nurs J. 2001;4(2):12-4. doi:10.1016/s1328-2743(01)80005-5.

4. Fernandes CM, Price A, Christenson JM. Does reduced length of stay decrease the number of emergency department patients who leave without seeing a physician? J Emerg Med. 1997;15(3):397-9. [PubMed: 9258798]

5. Vieth TL, Rhodes KV. The effect of crowding on access and quality in an academic ED. Am J Emerg Med. 2006;24(7):787-94. doi: 10.1016/j.ajem.2006.03.026. [PubMed:17098098]

6. Kyriacou DN, Ricketts V, Dyne PL, McCollough MD, Talan DA. A 5-Year Time Study Analysis of Emergency Department Patient Care Efficiency. Ann Emerg Med. 1999;34(3):326-35. doi: 10.1016| s0196-0644(99)70126-5. [PubMed:10459088]

7. Ng D, Vail G, Thomas S, Schmidt N. Applying the Lean principles of the Toyota Production System to reduce wait times in the emergency department. CJEM. 2010;12(1):50-7. [PubMed: 20078919]

8. Spaite DW, Bartholomeaux F, Guisto J, Lindberg E, Hull B, Eyherabide A, et al. Rapid process redesign in a university-based emergency department: decreasing waiting time intervals and improving patient satisfaction. Ann Emerg Med. 2002;39(2):168-77. [PubMed: 11823772]

9. McGillicuddy DC, O'Connell FJ, Shapiro NI, Calder SA, Mottley LJ, Roberts JC, et al. Emergency department abnormal vital sign "triggers" program improves time to therapy. Acad Emerg Med. 2011;18(5):4837. doi:10.1111/j.1553-2712.2011.01056.x. [PubMed: 21521399]

10. Paulson DL. A comparison of wait times and patients leaving without being seen when licensed nurses versus unlicensed assistive personnel perform triage. J Emerg Nurs. 2004;30(4):307-11. doi:10.1016/j.jen.2004.04.022. [PubMed:15282506]

11. Considine J, Ung L, Thomas S. Clinical decisions using the National Triage Scale: how important is postgraduate education? Accid Emerg Nurs. 2001;9(2):101-8. [PubMed:11760621]

12. Shelton R. The Emergency Severity Index 5-Level Triage System. Dimens Crit Care Nurs. 2009;28(1):9-12. doi: 10.1097/01. dcc.0000325106.28851.89. [PubMed:19104244]

13. Gilboy N, Tanabe P, Travers DA, Rosenau AM, Eitel DR. Emergency severity index, version 4: implementation handbook. Rockville: Agency for Healthcare Research and Quality; 2005.

14. Jafari-Rouhi AH, Sardashti S, Taghizadieh A, Soleimanpour H, Barzegar M. The Emergency Severity Index, version 4, for pedi- 
atric triage: a reliability study in Tabriz Children's Hospital, Tabriz, Iran. Int J Emerg Med. 2013;6(1):36. doi:10.1186/1865-1380-6-36. [PubMed: 24088367]

15. McHugh M, Tanabe P, McClelland M, Khare RK. More patients are triaged using the Emergency Severity Index than any other triage acuity system in the United States. Acad Emerg Med. 2012;19(1):1069. doi: 10.1111/j.1553-2712.2011.01240.x. [PubMed: 22211429]

16. Singer RF, Infante AA, Oppenheimer CC, West CA, Siegel B. The Use of and Satisfaction with the Emergency Severity Index. J Emerg Nurs. 2012;38(2):120-6. doi: 10.1016/j.jen.2010.07.004. [PubMed: 22401616]

17. Christ M, Grossmann F, WinterD, Bingisser R, Platz E. Modern triage in the emergency department. Dtsch Arztebl Int. 2010;107(50):8928. doi: 10.3238/arztebl.2010.0892. [PubMed:21246025]

18. Durani Y, Brecher D, Walmsley D, Attia MW, Loiselle JM. The Emergency Severity Index Version 4: reliability in pediatric patients. Pediatr Emerg Care. 2009;25(11):751-3. [PubMed: 19938298]

19. Mullan PC, Torrey SB, Chandra A, Caruso N, Kestler A. Reduced overtriage and undertriage with a new triage system in an urban accident and emergency department in Botswana: a cohort study. Emerg Med J. 2014;31(5):356-60. doi: 10.1136/ emermed-2012-201900. [PubMed: 23407375]

20. Krejcie RV, Morgan DW. Determining sample size for research activities. Educ Psychol Meas. 1970;30:607-10.

21. Azizi-Naghdlou F. Effect of Triage on Medical Services Waiting Time and Patient Satisfaction in Shahid Rajae Hospital Emergency Department in Karaj In 2006. Tehran: University of Social Welfare and Rehabilitation; 2007.

22. Hosseini M, Shaker H, Ghafouri H, Shokraneh F. Chronometric Study of Patients' Workflow and Effective Factors on It in Emergency Department of 7th Tir Martyrs Hospital of Tehran, Iran. $J$ Health Administr. 2010;13(40):13-22.

23. Eghdam H, Shirzad H, Majidi A. Chronometry Evaluation of Emergency Department in Shariati and Baharloo Hospitals. Tehran. Sixth Anuual Congress on Emergency Medicine; 2011.

24. Storrow AB, Zhou C, Gaddis G, Han JH, Miller K, Klubert D, et al. Decreasing lab turnaround time improves emergency department throughput and decreases emergency medical services diversion: a simulation model. Acad Emerg Med. 2008;15(11):1130-5. doi:10.1111/j.1553-2712.2008.00181.x. [PubMed:18638034] 